\title{
Response of base-isolated liquid storage tanks
}

\author{
M.B. Jadhav and R.S. Jangid* \\ Department of Civil Engineering, Indian Institute of Technology Bombay, Powai, Mumbai - 400076 India
}

Received 27 July 2002

Accepted 21 April 2003

\begin{abstract}
Seismic response of liquid storage tanks isolated by elastomeric bearings and sliding system is investigated under real earthquake ground motions. The continuous liquid mass of the tank is modeled as lumped masses known as sloshing mass, impulsive mass and rigid mass. The coupled differential equations of motion of the system are derived and solved in the incremental form using Newmark's step-by-step method with iterations. The seismic response of isolated tank is studied to investigate the comparative effectiveness of various isolation systems. A parametric study is also carried out to study the effect of important system parameters on the effectiveness of seismic isolation for liquid storage tanks. The various important parameters considered are: (i) aspect ratio of the tank and (ii) the time period of the isolation systems. It was observed that both elastomeric and sliding systems are found to be effective in reducing the earthquake forces of the liquid storage tanks. However, the elastomeric bearing with lead core is found to perform better in comparison to other systems. Further, an approximate model is proposed for evaluation of seismic response of base-isolated liquid storage tanks. A comparison of the seismic response evaluated by the proposed approximate method and an exact approach is made under different isolation systems and system parameters. It was observed that the proposed approximate analysis provides satisfactory response estimates of the base-isolated liquid storage tanks under earthquake excitation.
\end{abstract}

Keywords: Base isolation, liquid storage tank, elastomeric bearings, sliding system, approximate analysis, earthquake, system parameters

\section{Introduction}

Liquid storage tanks are strategically very important structures, since they have vital use in industries, nuclear power plants and other activities connected to the public life. There have been a number of reports on damage in liquid storage tanks in past earthquakes [1, 2]. The earthquake damage has been due to several causes, the most common being buckling of tank wall due to excessive development of compressive stresses in the wall, failure of piping system and uplift of the anchorage system. The integrity of any structure can be protected from the attack of severe earthquakes either through the concept of resistance or isolation. In designing a structure by resistance, it is assumed that the earthquake forces can be transmitted directly to the structure and each member of the structure is required

\footnotetext{
*Corresponding author. E-mail: rsjangid@civil.iitb.ac.in.
}

to resist the maximum possible forces that may be induced by earthquakes based on various ductility criteria. In the category of earthquake isolation, however, one is interested in reducing the peak response of the structure through implementation of certain isolation devices between the base and foundation of the structure.

The base isolation techniques have been developed and successfully implemented to buildings in the past $[3,4]$. However, there have been very few studies to investigate the effectiveness of base isolation for aseismic design of liquid storage tanks. Chalhoub and Kelly [5] conducted shaking table test on baseisolated cylindrical water tanks and compared the response with the corresponding response of non-isolated tanks. A significant reduction in hydrodynamic forces with slight increase of free-water surface was observed due to isolation. Liang and Jia-xiang [6] investigated the seismic response of flexible liquid storage tanks isolated by lead-rubber bearings. The investigation re- 


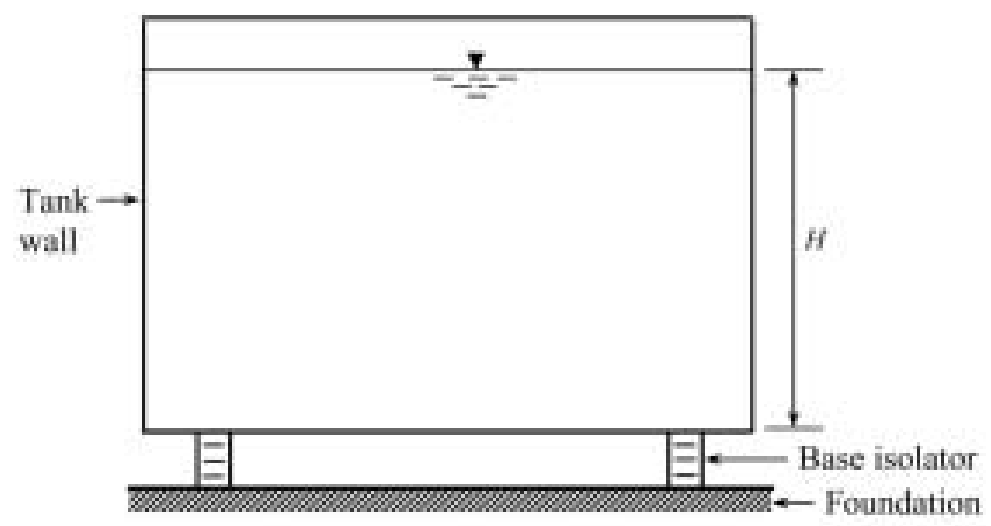

(a)

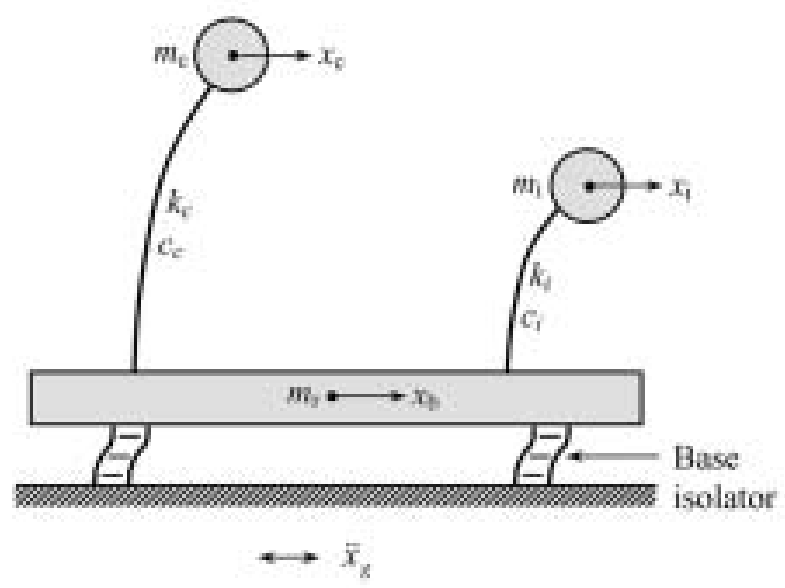

(b)

Fig. 1. Structural model of base-isolated liquid storage tank.

vealed that isolation was effective in reducing the seismic response of the tanks. Kim and Lee [7] experimentally investigated the seismic performance of liquid storage tanks isolated by laminated rubber bearings under uni-directional excitation and showed that the isolation was effective in reducing the daynamic response. Malhotra [8] studied the seismic response of cylindrical liquid storage tanks, under uni-directional ground motion, in which the wall of the tank was isolated from the base plate by horizontal flexible rubber bearings. The numerical results indicated that the isolation was quite effective in reducing the axial stresses in the cylindrical shell. The numerical results also indicated that the sloshing displacement of base-isolated liquid storage tank was increased but the decrease in axial stresses in the cylindrical shell was significant to avoid the buckling of the shell. Wang et al. [9] observed the seismic performance of liquid storage tank, isolated by friction pendulum system (FPS) under uni- directional excitation, and found that the isolation system was effective to reduce the response. Recently, Shrimali and Jangid [10] investigated the earthquake response of slender and broad liquid storage tanks isolated by sliding bearings and found that the response of the isolated tanks was reduced significantly.

Here-in, the seismic response of ground-supported liquid storage tanks isolated by elastomeric bearings and sliding system is investigated under real earthquake ground motions. The specific objectives of this study are: (i) To investigate the comparative effectiveness of various base isolation systems for aseismic design of liquid storage tanks; (ii) to study the influence of important system parameters on the effectiveness of base isolation for liquid storage tanks; and (iii) to propose a simplified approximate analysis for evaluation of the seismic response of base-isolated liquid storage tanks and study its feasibility considering different parameters of the tank. 


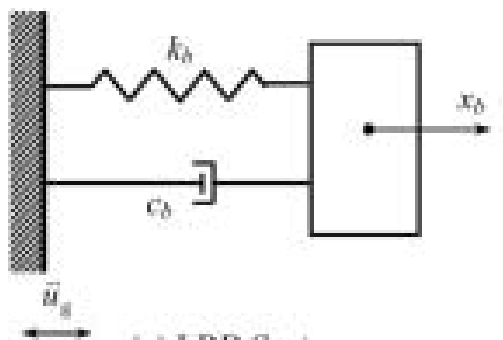

(a) LRB System

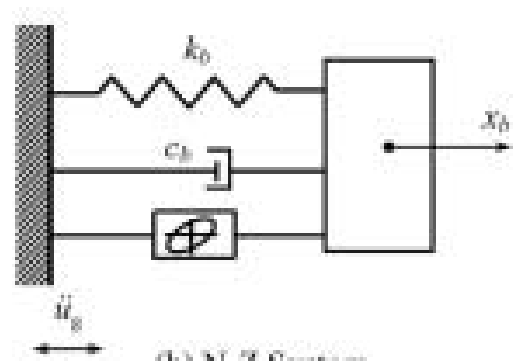

(b) N-Z System

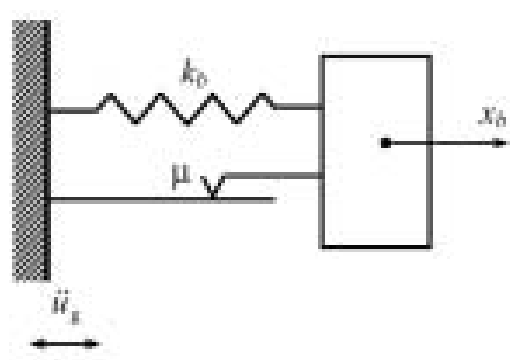

(c) FPS

Fig. 2. Various base isolation systems.

\section{Structural model of liquid storage tank}

Figure 1 shows the structural model of a baseisolated circular cylindrical liquid storage tank. The isolation bearings are installed between the base and foundation to isolate the tank. The tank liquid is considered as incompressible, inviscid and has irrotational flow. The base excitation vibrates the entire tank liquid in three distinct patterns, namely convective or sloshing mass (i.e. top liquid mass which changes the free liquid surface), impulsive mass (intermediate liquid mass vibrating with the tank wall) and rigid mass (i.e. lower tank liquid which rigidly moves with the tank wall). There are various modes in which sloshing and impulsive masses vibrate, but the response can be predicted by considering the first sloshing mode and the first impulsive mode, as observed experimentally by Kim and
Lee [7] and numerically by Malhotra [8,10]. Therefore, the tank liquid is modelled as lumped masses with flexible tank, according to Haroun's model [11], as shown in Fig. 1(b). The sloshing, impulsive and rigid masses are referred as $m_{c}, m_{i}$ and $m_{r}$, respectively. The sloshing and impulsive masses are connected to the tank wall by corresponding equivalent spring with stiffness constants $k_{c}$ and $k_{i}$, respectively. The damping constant of the sloshing and impulsive masses are $c_{c}$ and $c_{i}$, respectively. The system has three-degrees-offreedom under uni-directional earthquake ground motion. These degrees-of-freedom are denoted by $x_{c}, x_{i}$ and $x_{b}$, which characterize the relative displacements of sloshing, impulsive and rigid mass, respectively. Furthermore, self mass of the tank is neglected, since it is very small in comparison to effective mass of the tank liquid.

The geometrical parameters of the tank considered are the liquid height, $H$, the radius, $R$, and the average thickness of the tank wall, $t_{h}$. The lumped masses are expressed in terms of the liquid mass, $m$ as

$$
\begin{aligned}
& m_{c}=Y_{c} m \\
& m_{i}=Y_{i} m \\
& m_{r}=Y_{r} m \\
& m=\pi R^{2} H \rho_{w}
\end{aligned}
$$

where $\rho_{w}$ is the liquid mass density. The $Y_{c}, Y_{i}$ and $Y_{r}$ are the mass ratios which are function of the tank wall thickness and aspect ratio of the tank. For $t_{h} / R=$ 0.004 , the various mass ratios can be are expressed as [11]

$$
\begin{aligned}
Y_{c}= & 1.01327-0.87578 S+0.35708 S^{2} \\
& -0.06692 S^{2}+0.00439 S^{4} \\
Y_{i}= & -0.15467+1.21716 S-0.62839 S^{2} \\
& +0.14434 S^{3}-0.0125 S^{4} \\
Y_{r}= & -0.01599+0.86356 S-0.30941 S^{2} \\
& +0.04083 S^{3}
\end{aligned}
$$

where $S=H / R$ is the aspect ratio (i.e. ratio of the liquid height to radius of the tank).

The fundamental frequency of the impulsive mass, $\omega_{i}$, and of the sloshing mass, $\omega_{c}$, are given by following expressions [11]

$$
\omega_{i}=\frac{P}{H} \sqrt{\frac{E}{\rho_{s}}}
$$



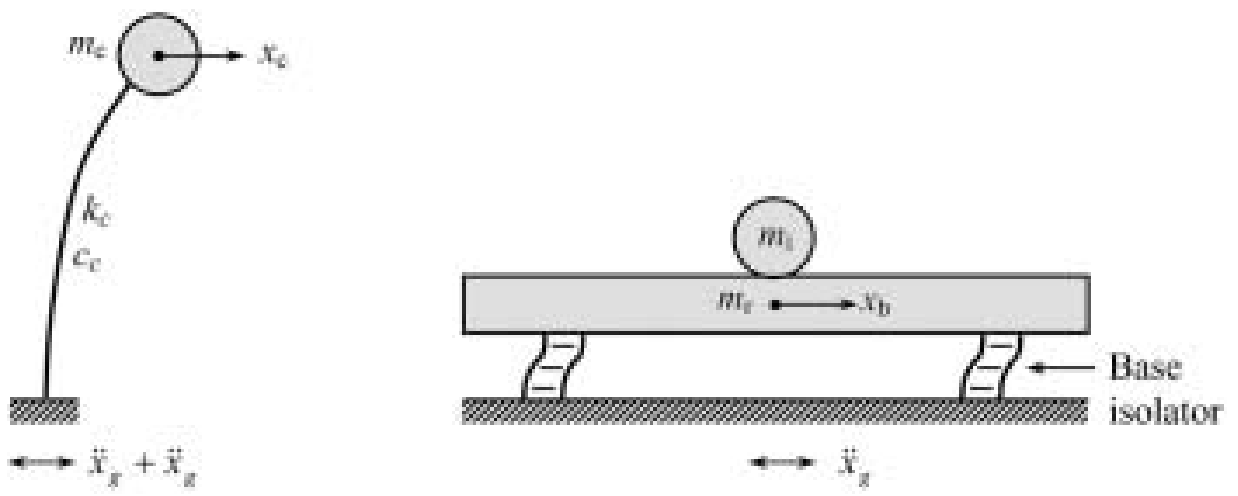

Fig. 3. Approximate proposed model of base-isolated liquid storage tank.

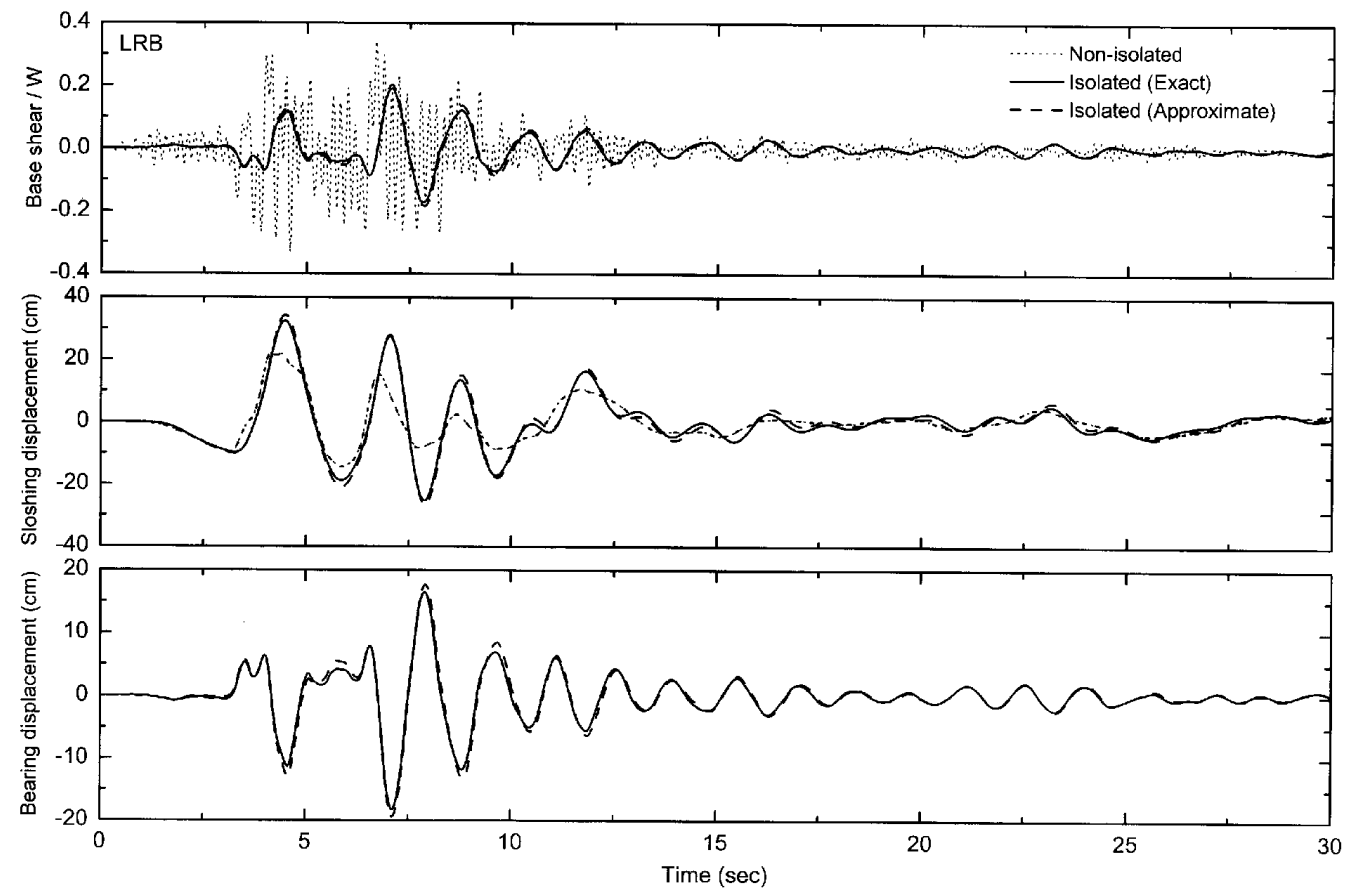

Fig. 4. Time variation of the response of broad tank isolated by LRB system under Northridge, 1994 earthquake motion $\left(S=0.6, T_{b}=2\right.$ sec and $\left.\xi_{b}=0.1\right)$.

$$
\omega_{c}=\sqrt{1.84\left(\frac{g}{R}\right) \tanh (1.84 S)}
$$

where $E$ and $\rho_{s}$ are the modulus of elasticity and density of the tank wall, respectively, $g$ is the acceleration due to gravity, and $P$ is a dimensionless parameter expressed by

$$
\begin{aligned}
P= & 0.037085+0.084302 S-0.05088 S^{2} \\
& +0.012523 S^{3}-0.0012 S^{4}
\end{aligned}
$$

The equivalent stiffness and damping constants of the sloshing and impulsive masses are expressed as

$$
\begin{aligned}
& k_{c}=m_{c} \omega_{c}^{2} \\
& k_{i}=m_{i} \omega_{i}^{2} \\
& c_{c}=2 \xi_{c} m_{c} \omega_{c} \\
& c_{i}=2 \xi_{i} m_{i} \omega_{i}
\end{aligned}
$$

where $\xi_{c}$ and $\xi_{i}$ are the damping ratios of the sloshing and impulsive masses, respectively. 


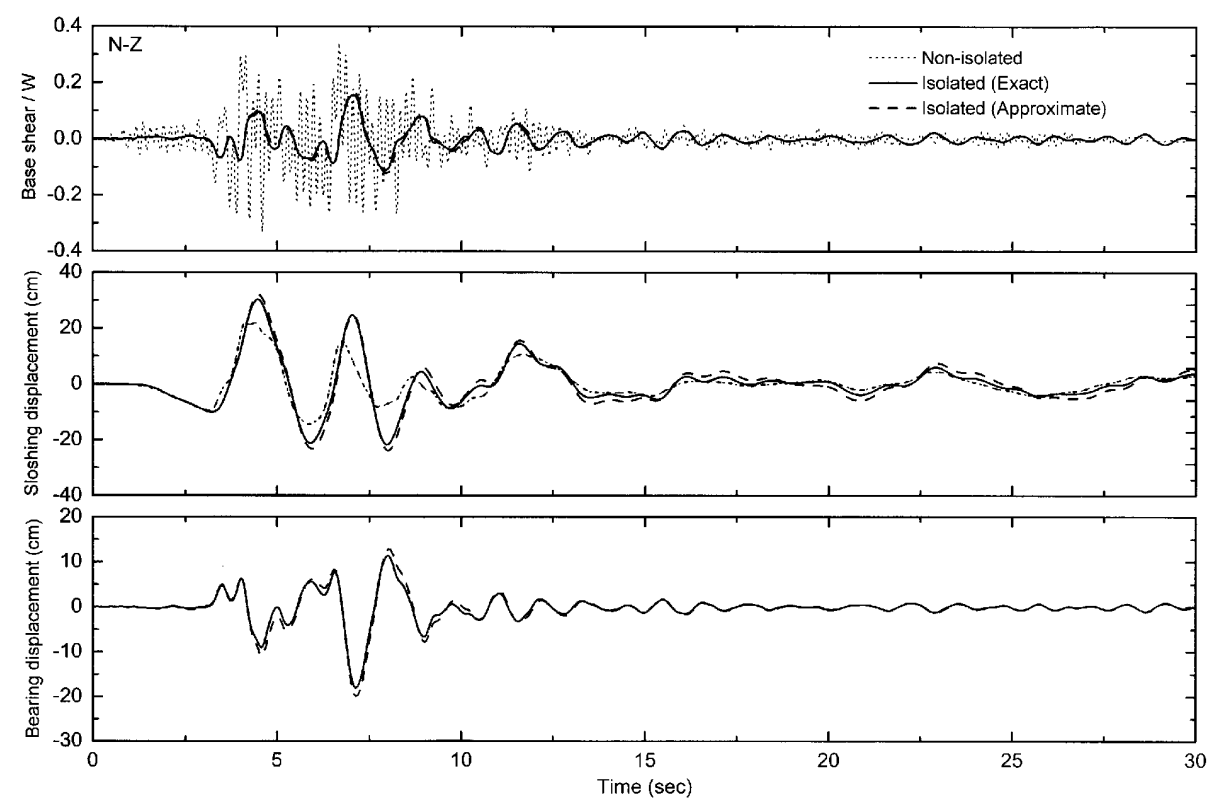

Fig. 5. Time variation of the response of broad tank isolated by N-Z system under Northridge, 1994 earthquake motion $\left(S=0.6, T_{b}=2.5\right.$ sec, $F_{0}=0.05$ and $\xi_{b}=0.1$ ).

\section{Governing equations of motion}

The equations of motion of isolated liquid storage tanks subjected to uni-directional earthquake ground motion are expressed for different systems as,

$$
\begin{aligned}
& m_{c} \ddot{x}_{c}+c_{c} \dot{x}_{c}+k_{c} x_{c}=-m_{c}\left(\ddot{x}_{b}+\ddot{x}_{g}\right) \\
& m_{1} \ddot{x}_{i}+c_{i} \dot{x}_{i}+k_{i} x_{i}=-m_{i}\left(\ddot{x}_{b}+\ddot{x}_{g}\right) \\
& \left(m_{c}+m_{i}+m_{r}\right) \ddot{x}_{b}+F_{b} \\
& =-\left(m_{c}+m_{i}+m_{r}\right) \ddot{x}_{g}
\end{aligned}
$$

where $x_{c}$ and $x_{i}$ are the horizontal displacements of the sloshing and impulsive masses relative to bearing displacement, respectively, $x_{b}$ is the displacement of the bearings relative to ground, $F_{b}$ is the restoring force of the isolation bearings andis the earthquake acceleration.

The restoring force, $F_{b}$, depends upon the type of isolation system considered and it is described as follows for different systems.

\subsection{Laminated rubber bearings}

The laminated rubber bearings (LRB) is the most common base isolated system. The basic components of the LRB are steel and rubber plates built in alternate layers. The dominant feature of the LRB sys- tem is the parallel action of linear spring and damping (Fig. 2(a)). Generally, the LRB system exhibits highdamping capacity, horizontal flexibility and high vertical stiffness. The LRB system is modeled with linear force-deformation behaviour and viscous damping. The restoring force is expressed by

$$
F_{b}=c_{b} \dot{x}_{b}+k_{b} x_{b}
$$

where $c_{b}$ and $k_{b}$ are the damping and stiffness constants of the LRB system, respectively.

The stiffness and damping of the LRB system is designed to provide specific values of two parameters, namely the period of isolation, $T_{b}$, and the damping ratio, $\xi_{b}$, expressed as

$$
\begin{aligned}
T_{b} & =2 \pi \sqrt{\frac{M}{k_{b}}} \\
\xi_{b} & =\frac{c_{b}}{2 M \omega_{b}}
\end{aligned}
$$

where $M=m_{c}+m_{i}+m_{r}$ is the effective mass of the liquid storage tank and $\omega_{b}=2 \pi / T_{b}$ is the base isolation frequency.

\subsection{Lead-rubber bearings}

These lead-rubber bearings are similar to the LRB but a central lead core is used to provide an additional means of energy dissipation and initial rigidity against 


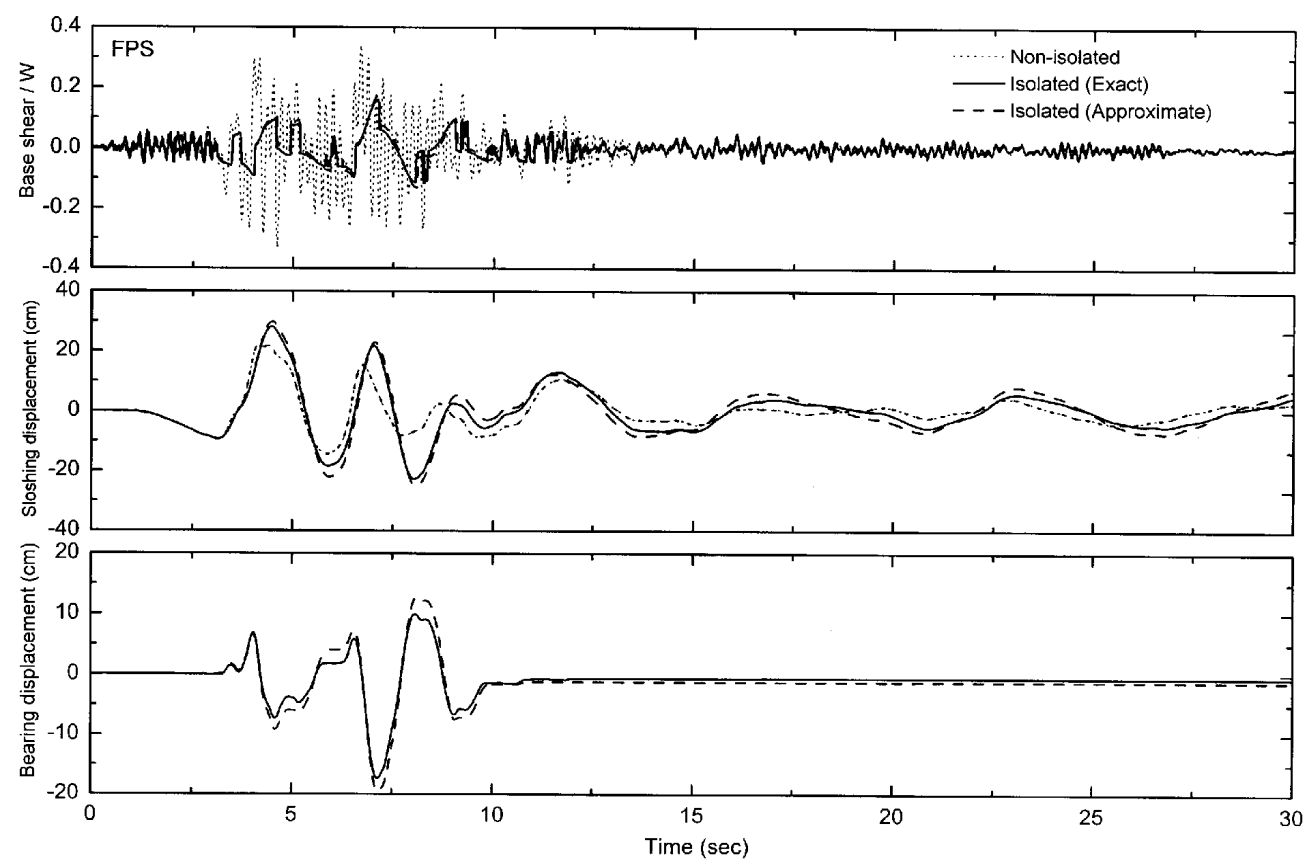

Fig. 6. Time variation of the response of broad tank isolated by FPS system under Northridge, 1994 earthquake motion $\left(S=0.6, T_{b}=2.5\right.$ sec and $\mu=0.05$ )
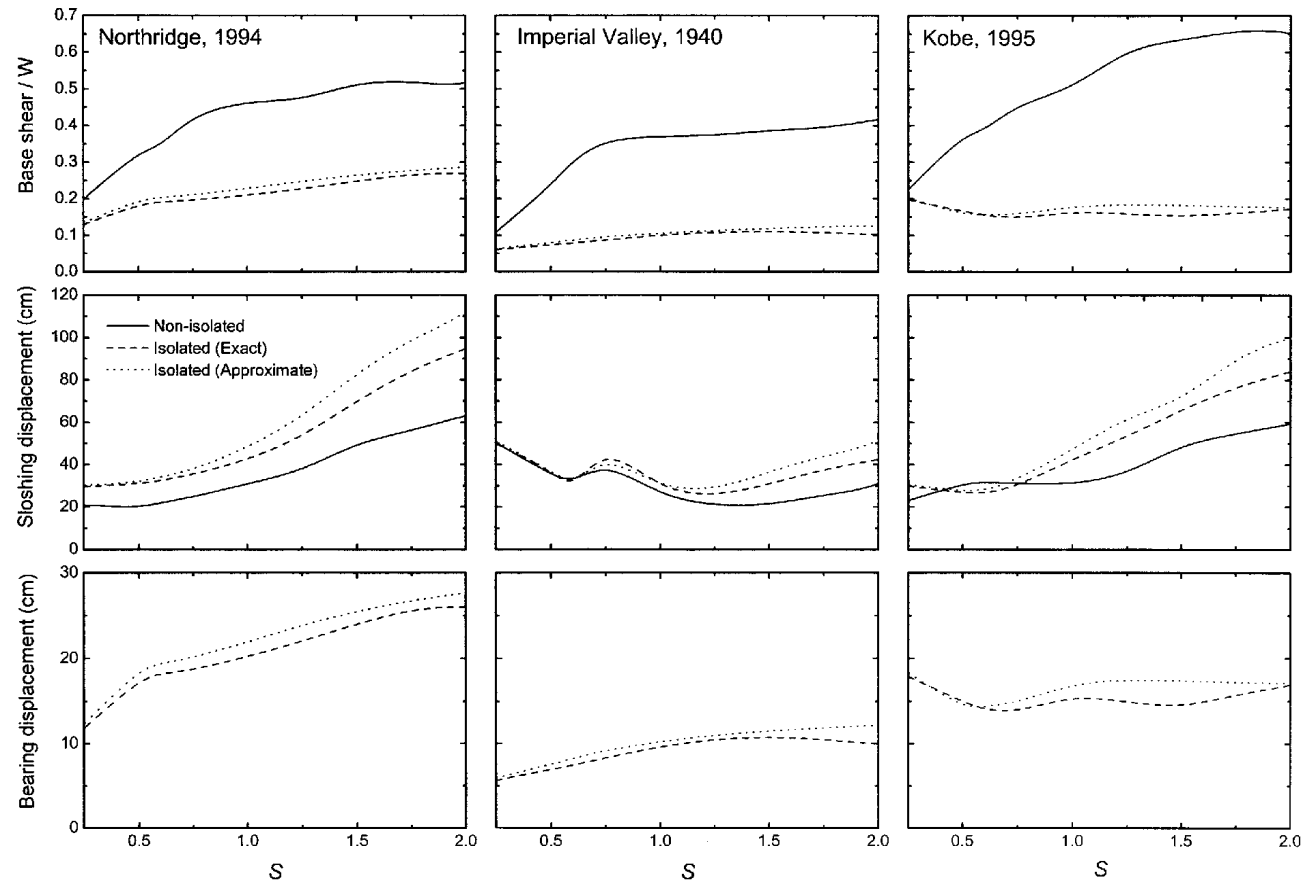

Fig. 7. Effects of aspect ratio on the peak response of tank isolated by LRB system $\left(T_{b}=2 \sec\right.$ and $\left.\xi_{b}=0.1\right)$.

minor earthquakes and winds [12]. These devices are widely used in New Zealand and are generally referred as $\mathrm{N}-\mathrm{Z}$ system. The energy absorbing capacity by the lead core reduces the lateral displacements of the isolator. The lead-rubber bearings also provide an additional hysteretic damping through the yielding of the 

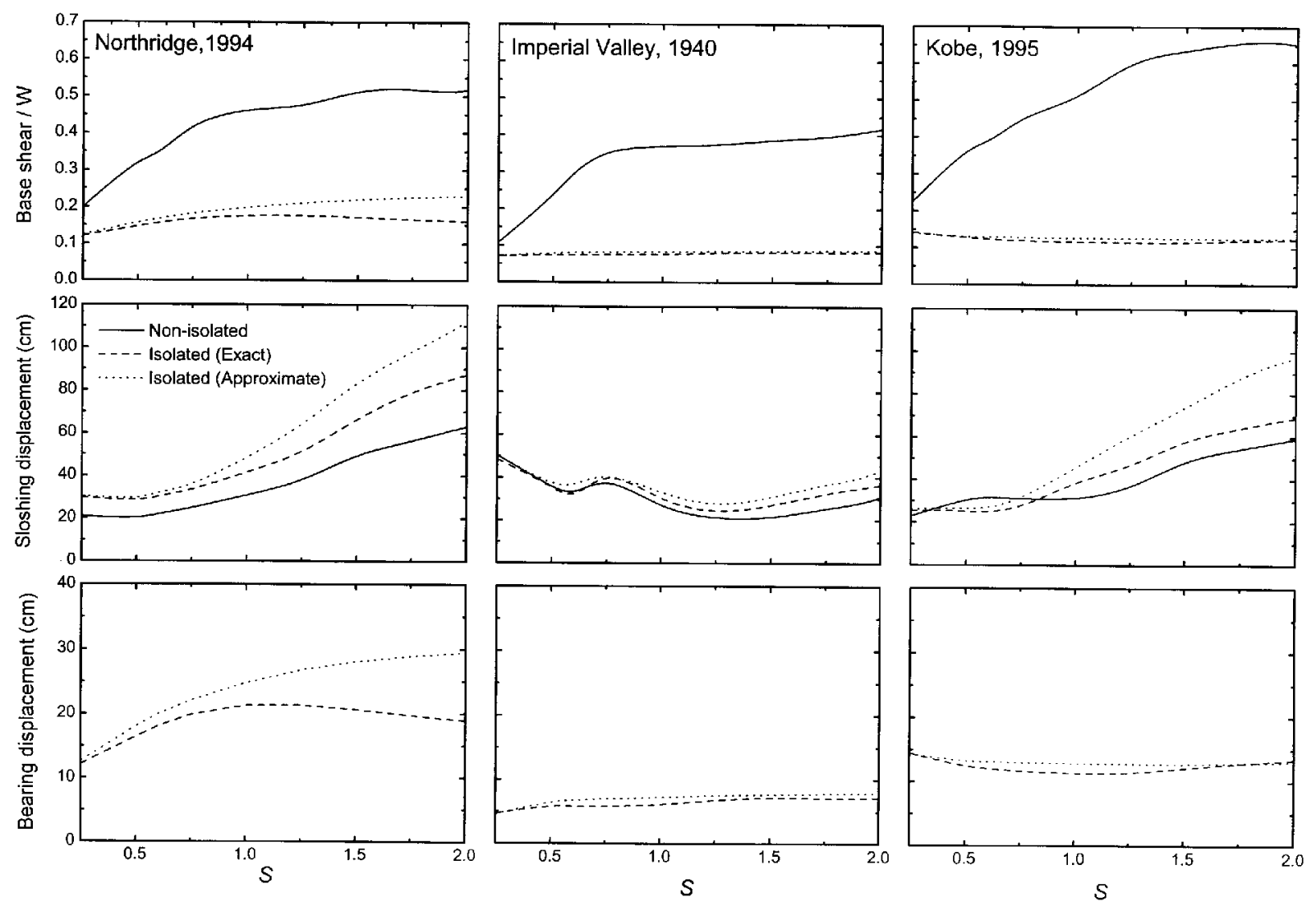

Fig. 8. Effects of aspect ratio on the peak response of tank isolated by N-Z system $\left(T_{b}=2.5 \mathrm{sec}, F_{0}=0.05\right.$ and $\left.\xi_{b}=0.1\right)$.

lead core. The hysteresis loop of a bearing is generally modelled by bi-linear force-deformation behaviour expressed by the Wen's equation [13]. The restoring force is expressed by

$$
F_{b}=c_{b} \dot{x}_{b}+\alpha k_{b} x_{b}+(1-\alpha) F_{y} Z
$$

where $c_{b}$ is the viscous damping of the bearing due to rubber or due to additional viscous dampers provided in parallel with the bearings $k_{b}$ is the initial stiffness of the bearing, $\alpha$ represents the ratio of post to pre-yielding stiffness, $F_{y}$ is the yield strength of the bearing and $Z$ is a non-dimensional hysteretic component satisfying the following non-linear first order differential equation,

$$
q \frac{d Z}{d t}=A \dot{x}_{b}+\beta\left|\dot{x}_{b}\right| Z|Z|^{n-1}-\tau \dot{x}_{b}|Z|^{n}
$$

where $q$ is the yield displacement of the bearing, $\beta$, $\tau, A$ and $n$ are the non-dimensional parameters of the hysteresis loop. The parameters $\alpha, \beta, \tau, A$ and $\mathrm{n}$ control the shape of the loop and are selected such that the predicted response from the model closely matches with the experimental results [14].
The lead-rubber bearings are generally designed to achieve specified values of three parameters namely: the isolation period, $T_{b}$, the damping ratio, $\xi_{b}$, and the normalized yield strength, $F_{0}$. The parameters $T_{b}$ and $\xi_{b}$ are obtained from Eqs (19) and (20), respectively, based on the post-yield stiffness of the bearing. The parameter $F_{0}$ is defined as

$$
F_{0}=\frac{F_{y}}{W}
$$

where $W=M g$ is the effective weight of the tank and $g$ is the acceleration due to gravity. The other parameters of the N-Z system are the yield displacement level of the bearing, $q$ and the parameters of the hysteresis loop such as $\beta, \tau, A$ and $n$. However, these parameters are held constant and the values taken are: $q=25 \mathrm{~mm}$, $\beta=\tau=0.5, A=1$ and $n=2$. The ratio of post to pre-yielding stiffness is computed using the expression $\alpha=\omega_{b}^{2} M q / F_{y}$.

\subsection{Friction pendulum system}

The friction pendulum system (FPS) is equipped with recentring force provided by the gravitational ac- 

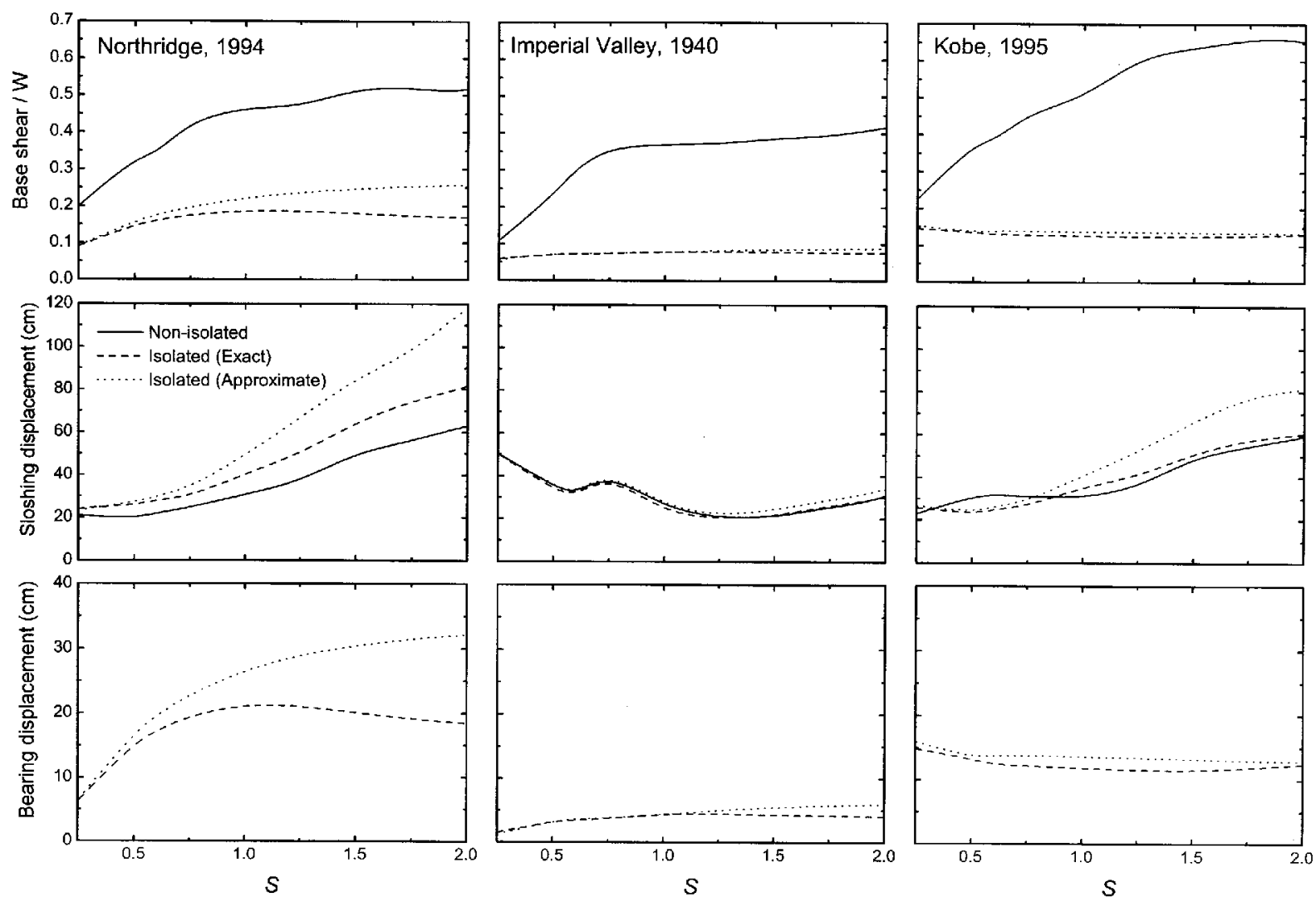

Fig. 9. Effects of aspect ratio on the peak response of tank isolated by FPS system $\left(T_{b}=2.5 \sec\right.$ and $\left.\mu=0.05\right)$.

tion, which is achieved by means of an articulated slider on spherical concave chrome surface [14]. The schematic diagram of FPS is shown in Fig. 2(c). The natural period of the isolation bearing is controlled by selection of the radius of curvature of the concave surface. The resisting force provided by the system is expressed as

$$
F_{b}=k_{b} x_{b}+F_{x}
$$

where $k_{b}$ is the stiffness of the FPS provided through inward gravity action and $F_{x}$ is the frictional force developed in the FPS.

The limiting value of the frictional force, $F_{s}$, to which the sliding system can be subjected (before sliding) is expressed as

$$
F_{s}=\mu M g
$$

where $\mu$ is the friction coefficient of the sliding system.

The stiffness of the system or curvature of sliding is adjusted such that it provides the specified value of the isolation period, $T_{b}$ based on Eq. (19). Thus, the parameters of the FPS system requires the specification of $T_{b}$ and $\mu$

\section{Solution of equations of motion}

The governing equations of motion of the structure isolated by different isolation systems cannot be solved using the classical modal superposition technique as (i) the damping in the isolation system and superstructure is different in nature because of material characteristics and (ii) the force-deformation behaviour of the N-Z and sliding systems is non-linear. As a result, the governing equations of motion are solved in the incremental form using Newmark's step-by-step method assuming linear variation of acceleration over small time interval, $\Delta t$. The time interval for solving the equations of motion is taken as $0.02 / 20 \mathrm{sec}$ (i.e. $\Delta t=0.001$ $\mathrm{sec})$. The incremental governing equations of motion of the tank with N-Z system are solved using the iterative technique. The iteration are required due to dependence of incremental hysteretic displacement, $\Delta Z$, on the response of the system at the end of time step. The detailed solution procedure of above method for one-story building supported on $\mathrm{N}-\mathrm{Z}$ system are given in Reference [16], which can easily be extended for the liquid storage tanks. 

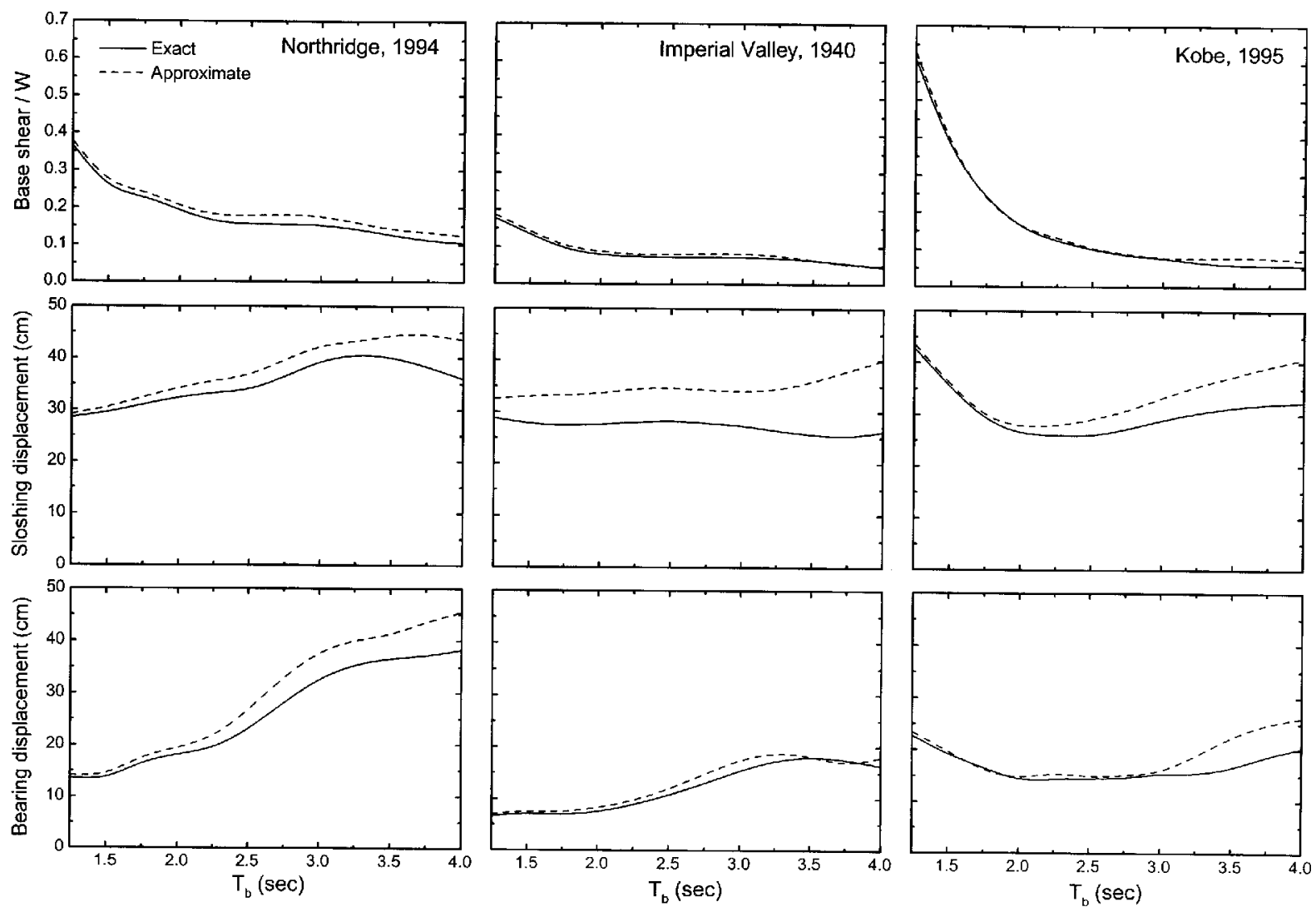

Fig. 10. Effects of isolation period on the peak response of broad tank isolated by LRB system $(S=0.6$ and $\xi=0.1)$.

For structures with sliding systems, at the end of each time interval of sliding phase the condition for sliding/non-sliding phase are duly checked and only the relevant equations of motion are considered in the analysis. The system remains in the non-sliding phase $\left(\dot{x}_{b}=\ddot{x}_{b}=0\right.$ ) if the frictional force mobilized at the interface of the sliding system is less than the limiting frictional force (i.e. $\left|F_{x}\right|<\left|F_{s}\right|$ ). However, the system starts sliding $\left(\dot{x}_{b} \neq 0\right.$ and $\left.\ddot{x}_{b} \neq 0\right)$ as soon as the frictional force attains the limiting frictional force (i.e. $\left|F_{x}\right|=F_{s}$ ). During the sliding phase, whenever the relative velocity of the base mass becomes zero (i.e. $\dot{x}_{b}=0$ ), the phase of the motion checked in order to determine whether the system remains in the sliding phase or sticks to the foundation.

The total base shear generated due to earthquake ground motion in horizontal direction, is expressed as

$$
\begin{aligned}
F_{s}= & m_{c}\left(\ddot{x}_{c}+\ddot{x}_{b}+\ddot{x}_{g}\right)+m_{i}\left(\ddot{x}_{i}+\ddot{x}_{b}+\ddot{x}_{g}\right) \\
& +m_{r}\left(\ddot{x}_{b}+\ddot{x}_{g}\right)
\end{aligned}
$$

\section{Approximate model base-isolated tanks}

The mathematical model of isolated tanks as shown in Fig. 1(b) has typical characteristics. In particular, the period of sloshing and impulsive masses are significantly larger and shorter as compared to the period of isolation, respectively. As a result, are can assumes that the sloshing mass vibrates independently and the impulsive mass rigidly moves along with the rigid tank mass associated with the bearing degree-of-freedom. Keeping the above in view, an approximated model for the base-isolated liquid storage tank is presented in Fig. 3. This simplified model consists of the analysis of two single degree-of-freedom systems. The sloshing mass is subjected to a base acceleration of and the impulsive mass is combined with the rigid mass associated to the isolation degree-of-freedom. The base shear generated due to earthquake ground motion in the isolated tank is evaluated by

$$
F_{s}=\left(m_{i}+m_{r}\right)\left(\ddot{x}_{b}+\ddot{x}_{g}\right)
$$



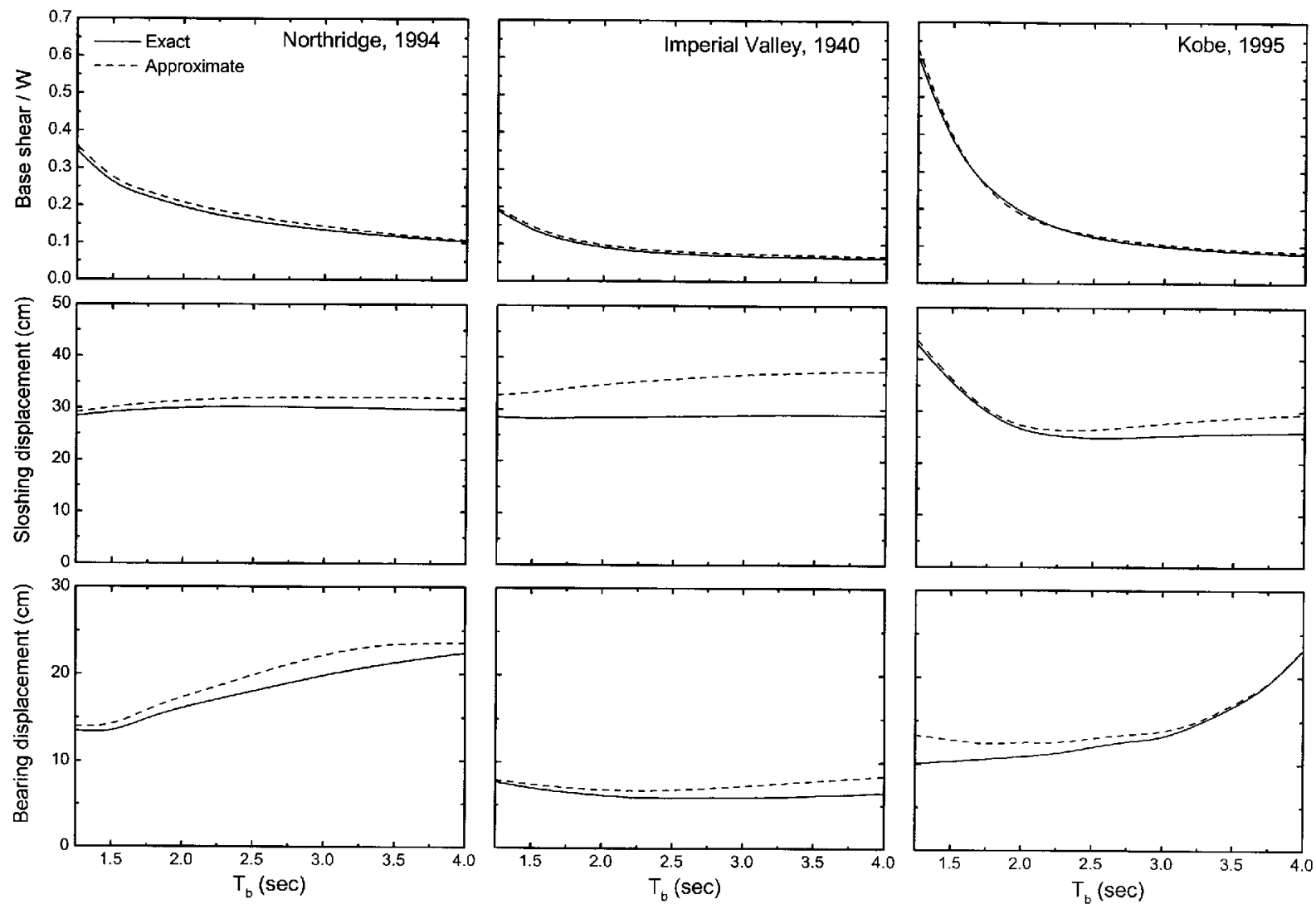

Fig. 11. Effects of isolation period on the peak response of broad tank isolated by N-Z system $\left(S=0.6, F_{0}=0.05\right.$ and $\left.\xi_{b}=0.1\right)$.

\section{Numerical study}

The response of liquid storage tanks isolated by different isolation systems is investigated under real earthquake ground motions. The earthquake motions considered are: SOOE component of Imperial Valley, 1940 (El-Centro), S00E component of Northridge, 1994 (Sylmar) and N90E component of Kobe, 1995 (JMA) earthquake. The peak acceleration of Imperial Valley, Northridge and Kobe earthquake motions are $0.35 \mathrm{~g}, 0.59 \mathrm{~g}$ and $0.63 \mathrm{~g}$, respectively. The response quantities of interest are base shear $\left(F_{s}\right)$, relative sloshing displacement $\left(x_{c}\right)$ and bearing displacement $\left(x_{b}\right)$. The response of the isolated tank system is compared with the corresponding response of non-isolated tank in order to study the effectiveness of various base isolation systems (i.e. LRB, N-Z and FPS). Further, the response of the isolated tank model given in Fig. 1 (referred as "Exact") is also compared with the response of the model proposed in Fig. 2 (referred as Approximate) to study the feasibility of the proposed model.

The parameters, which characterize the model of liquid storage tank, are the height of liquid in the tank $(H)$, the aspect ratio $(S)$, the damping ratio of the sloshing mass $\left(\xi_{c}\right)$ and the damping ratio of the impulsive mass $\left(\xi_{i}\right)$. The height of the liquid in the tank, $H=10 \mathrm{~m}$, is kept constant throughout the study. The damping ratios for the sloshing and impulsive masses are taken as 0.5 and 2 percent, respectively. For the tanks with steel wall, the modulus of elasticity is taken as $E=200 \mathrm{GPa}$ and the mass density $\rho_{s}=7,900 \mathrm{~kg} / \mathrm{m}^{3}$.

The time variation of various response quantities of a broad tank isolated by the LRB system is shown in Fig. 4 under Northridge, 1994 earthquake ground motion. The parameters of the LRB system considered are: $T_{b}=2 \mathrm{sec}$ and $\xi_{b}=0.1$. It is observed from the figure that due to base isolation there is significant reduction in the base shear implying that the base isolation is effective for liquid storage tanks. However, there is slight increase in the sloshing displacement due to base isolation. Further, the exact response of isolated tanks is well comparable with the approximate response obtained from the proposed model in Fig. 2. Thus, it can be concluded that satisfactory response can be obtained by using the proposed approximate anal- 

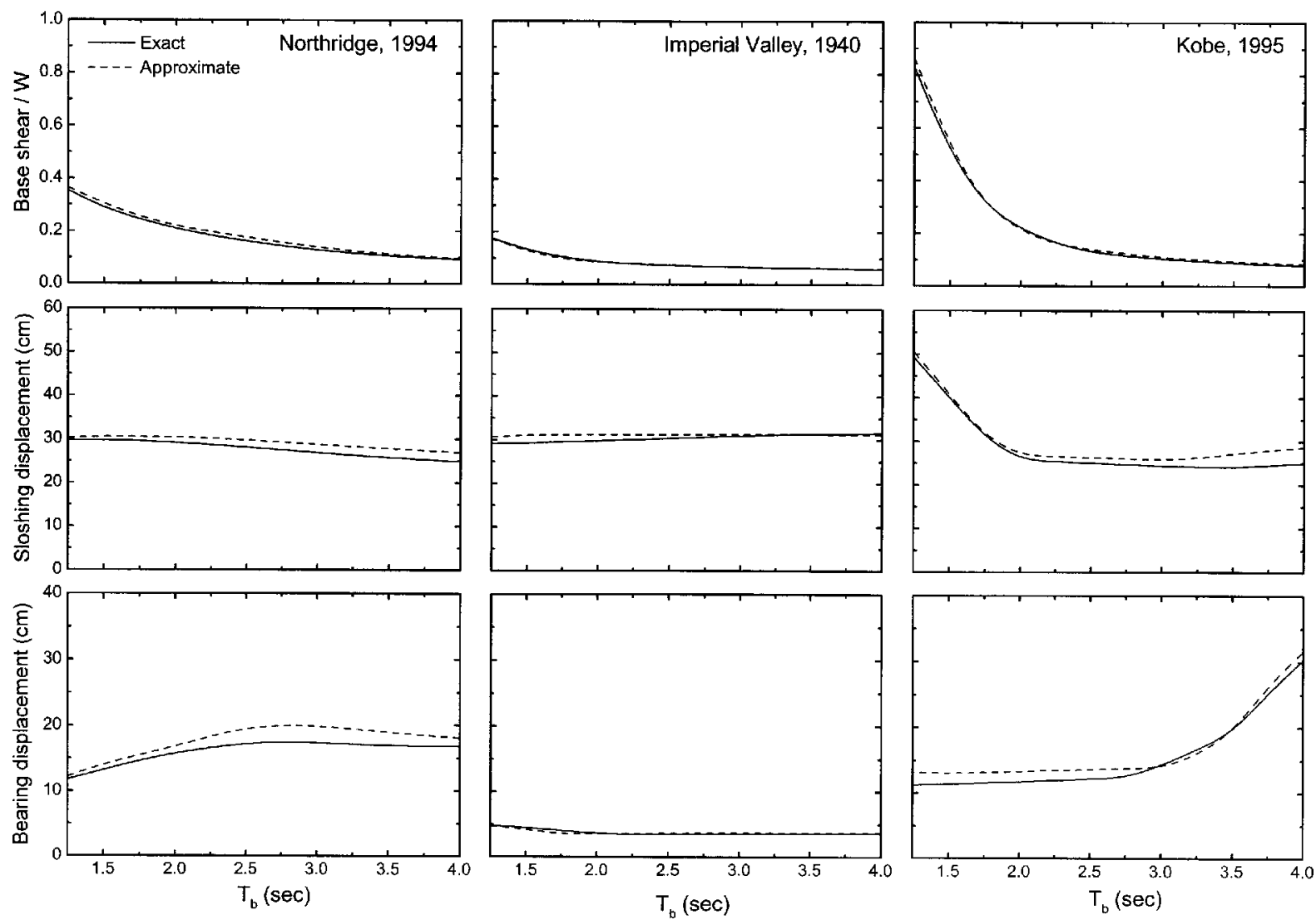

Fig. 12. Effects of isolation period on the peak response of broad tank isolated by FPS system $(S=0.6$ and $\mu=0.05)$.

ysis of the base-isolated liquid storage tanks. Similar effects of base isolation and comparison of exact and approximate response of isolated broad tank are depicted in Figs 5 and 6 showing the response of the tank isolated N-Z $\left(T_{b}=2.5 \mathrm{sec} \xi_{b}=0.1\right.$ and $\left.F_{0}=0.05\right)$ and FPS ( $T_{b}=2.5$ and $\left.\mu=0.05\right)$, respectively.

The peak response for broad tank $(S=0.6)$ and slender tank $(S=2)$ is shown in Tables 1 and 2, respectively under different earthquake motions. The response of three isolation systems is shown for both nonisolated and isolated (exact as well as approximate) conditions. It is observed from these tables that there is good agreement between the exact and approximate response of base-isolated tank under different earthquake motions. Further, the reduction in base shear is found to be more significant for the slender tank in comparison to the broad tank. Thus, the base isolation is more effective for slender tanks as compared to broad tanks. From Tables 1 and 2, it is also observed that the N-Z and FPS system performs better than the LRB systems. These systems provide more reduction in the base shear with less sloshing and bearing displacements.
The variation of peak response of the tank isolated by LRB, N-Z and FPS against aspect ratio, $S$ is shown in Figs 7, 8 and 9, respectively. The aspect ratio is varied from 0.25 to 2 to obtain the response of non-isolated and isolated tanks. It is observed that the base shear is effectively reduced due to isolation and as the aspect ratio increases the base shear, bearing displacement and convective displacement increases. It shows that the base shear and bearing displacement in case of broad tank is less compared to slender tank. The base shear obtained from exact and approximate analyse closely matches for all the earthquake motions and isolations systems. Further, there is not in general a very significant difference between the sloshing displacement for isolated and non-isolated condition. The sloshing displacement due to isolation increases with the increase of the tank aspect ratio. The difference in the sloshing displacement evaluated by exact and approximate method increase with the increase of the aspect ratio. This is expected due to fact that, as the aspect ratio increases, the sloshing and isolation frequency occurs closer leading to strong coupling between the sloshing 
Table 1

Peak response of broad tank for different isolation systems $(S=0.6)$

\begin{tabular}{|c|c|c|c|c|c|c|c|c|}
\hline \multirow[t]{3}{*}{ Earthquake } & \multirow[t]{3}{*}{ Response quantities } & \multirow[t]{3}{*}{ Non -isolated } & \multicolumn{6}{|c|}{ Isolated Tank } \\
\hline & & & \multicolumn{2}{|r|}{ LRB } & \multicolumn{2}{|c|}{$\mathrm{N}-\mathrm{Z}$} & \multicolumn{2}{|c|}{ FPS } \\
\hline & & & Exact & Approximate & Exact & Approximate & Exact & Approximate \\
\hline Northridge, 1994 & $\begin{array}{c}F_{s} / W \\
x_{c}(\mathrm{~cm}) \\
x_{b}(\mathrm{~cm})\end{array}$ & $\begin{array}{c}0.341 \\
22.00 \\
-\end{array}$ & $\begin{array}{c}0.191 \\
32.43 \\
18.24\end{array}$ & $\begin{array}{l}0.203 \\
34.27 \\
19.42\end{array}$ & $\begin{array}{c}0.157 \\
30.24 \\
18.05\end{array}$ & $\begin{array}{c}0.169 \\
31.96 \\
19.91\end{array}$ & $\begin{array}{c}0.160 \\
28.07 \\
17.23\end{array}$ & $\begin{array}{l}0.176 \\
29.74 \\
19.59\end{array}$ \\
\hline Imperial Valley, 1940 & $\begin{array}{c}F_{s} / W \\
x_{c}(\mathrm{~m}) \\
x_{b}(\mathrm{~cm})\end{array}$ & $\begin{array}{c}0.304 \\
31.20 \\
-\end{array}$ & $\begin{array}{c}0.078 \\
27.63 \\
7.43\end{array}$ & $\begin{array}{c}0.086 \\
31.20 \\
8.27\end{array}$ & $\begin{array}{c}0.074 \\
28.64 \\
5.85\end{array}$ & $\begin{array}{c}0.080 \\
30.88 \\
6.77\end{array}$ & $\begin{array}{c}0.072 \\
30.35 \\
3.52\end{array}$ & $\begin{array}{c}0.073 \\
31.26 \\
3.66\end{array}$ \\
\hline Kobe, 1995 & $\begin{array}{c}\mathrm{Fs} / \mathrm{W} \\
x_{c}(\mathrm{~cm}) \\
x_{b}(\mathrm{~cm})\end{array}$ & $\begin{array}{c}0.385 \\
31.87 \\
-\end{array}$ & $\begin{array}{l}0.155 \\
26.20 \\
14.00\end{array}$ & $\begin{array}{l}0.156 \\
27.63 \\
14.36\end{array}$ & $\begin{array}{l}0.123 \\
24.86 \\
12.07\end{array}$ & $\begin{array}{l}0.129 \\
26.38 \\
13.17\end{array}$ & $\begin{array}{l}0.129 \\
25.03 \\
12.42\end{array}$ & $\begin{array}{l}0.138 \\
26.28 \\
13.81\end{array}$ \\
\hline
\end{tabular}

Table 2

Peak response of broad tank for different isolation systems $(S=2)$

\begin{tabular}{|c|c|c|c|c|c|c|c|c|}
\hline \multirow[t]{3}{*}{ Earthquake } & \multirow[t]{3}{*}{ Response quantities } & \multirow[t]{3}{*}{ Non -isolated } & \multicolumn{6}{|c|}{ Isolated Tank } \\
\hline & & & \multicolumn{2}{|r|}{ LRB } & \multicolumn{2}{|c|}{$\mathrm{N}-\mathrm{Z}$} & \multicolumn{2}{|r|}{ FPS } \\
\hline & & & Exact & Approximate & Exact & Approximate & Exact & Approximate \\
\hline \multirow[t]{3}{*}{ Northridge, 1994} & $F_{s} / \mathrm{W}$ & 0.503 & 0.271 & 0.286 & 0.161 & 0.229 & 0.168 & 0.257 \\
\hline & $x_{c}(\mathrm{~cm})$ & 63.52 & 94.83 & 110.12 & 87.46 & 111.33 & 80.99 & 119.24 \\
\hline & $x_{b}(\mathrm{~cm})$ & - & 26.20 & 27.68 & 18.90 & 29.46 & 18.40 & 32.15 \\
\hline \multirow[t]{3}{*}{ Imperial Valley, 1940} & $F_{s} / \mathrm{W}$ & 0.417 & 0.101 & 0.126 & 0.082 & 0.086 & 0.076 & 0.088 \\
\hline & $x_{c}(\mathrm{~m})$ & 29.05 & 42.43 & 49.23 & 36.44 & 40.98 & 29.49 & 32.64 \\
\hline & $x_{b}(\mathrm{~cm})$ & - & 9.86 & 12.16 & 7.16 & 7.91 & 4.05 & 5.97 \\
\hline \multirow[t]{3}{*}{ Kobe, 1995} & $F_{s} / \mathrm{W}$ & 0.662 & 0.171 & 0.175 & 0.123 & 0.125 & 0.130 & 0.133 \\
\hline & $x_{c}(\mathrm{~cm})$ & 59.45 & 84.32 & 101.28 & 69.57 & 98.57 & 60.90 & 81.81 \\
\hline & $x_{b}(\mathrm{~cm})$ & - & 16.82 & 17.11 & 13.48 & 13.16 & 12.47 & 12.90 \\
\hline
\end{tabular}

and isolation mode. Since the approximate analysis ignores this coupling, the error is more significant for higher aspect ratio. The bearing displacement obtained from exact and approximate analyses closely matches, in general, and the approximate analysis gives slightly conservative estimate (although the difference is relatively higher in case of Northridge, 1994 earthquake motion). The proposed approximate analysis performs better for broad tanks in comparison to slender tanks.

The effect of isolation period of LRB, N-Z and FPS on the peak response of base-isolated tank is shown in Figs 10, 11 and 12, respectively. The isolation time period, $T_{b}$, is varied from $1.25 \mathrm{sec}$ to $4 \mathrm{sec}$ for a broad tank with aspect ratio $S=0.6$. These figures confirm good comparison between the exact and approximate response of isolated tank for all earthquakes and isolation systems. Further, it is also observed from Figs 10 to 12 that the base shear decreases with the increase of isolation period. Thus, the effectiveness of base isolation increases with the increase of its flexibility. On the other hand, the bearing displacements are also relatively higher for the higher values of isolation period. Thus, the earthquake forces transmitted to the tank system can be reduced at the expense of increasing dis- placement of the isolation system. However, the displacement of the isolation systems has a practical limitation. Therefore, in designing the isolation system a compromise shall be made between transmitted earthquake forces and relative bearing displacements. Further, the comparison of response of the isolated tanks with different earthquake motion in Figs 10 to 12 implies that variation of response against the period of isolator. $T_{b}$ is sensitive to the specific characteristic of these types of earthquake motion. The variation of the response is in accordance to the variation of the response spectrum of the earthquake motions (refer Reference [17] for the displacement and acceleration spectra of all the three earthquake motions).

\section{Conclusions}

The seismic response of liquid storage tanks isolated by LRB, N-Z and FPS systems is investigated under real earthquake ground motion. In order to investigate the effectiveness of base isolation, the response of the isolated tank is compared with the corresponding response of tank without isolation system. An approxi- 
mate model is also proposed for evaluation of the seismic response of base-isolated liquid storage tanks. A parametric study is conducted to investigate the effects of important parameters on the effectiveness of base isolation and the accuracy of the proposed approximate method. From the trends of the results of the present study, the following conclusions can be drawn:

1. All the three base isolation systems are found to be effective in reducing the earthquake forces of the liquid storage tanks. However, the N-Z system is found to be better in comparison to the LRB and FPS systems.

2. The base isolation is found to be more effective for slender tanks in comparison to broad tanks for all isolation systems. There is also increase in the sloshing displacement for slender tanks due to base isolation.

3. The base shear, sloshing displacement and bearing displacement obtained from exact and approximate analysis are closely matches. Thus, the proposed approximate analysis of the baseisolated liquid storage tanks provides satisfactory response under earthquake excitation.

4. The proposed approximate analysis is found to perform better in case of broad tanks in comparison to slender tanks.

5. The effectiveness of seismic isolation systems increases with the increase in the time period of isolation systems. However, the bearing displacements are also relatively higher for the higher values of isolation period.

\section{References}

[1] K.V. Steinbrugge and F.A. Rodrigo, The Chilean earthquake of May 1960: A structural engineering viewpoint, Bulletin of Seismological Society of America 53 (1963), 225-307.

[2] A. Niwa and R.W. Clough, Buckling of cylindrical liquidstorage tanks under earthquake loading, Earthquake Engineer- ing and Structural Dynamics 10 (1982), 107-122.

[3] J.M. Kelly, A seismic base isolation: Review and bibliography, Soil dynamics and Earthquake Engineering 5 (1986), 202216.

[4] R.S. Jangid and T.K. Datta, Seismic behaviour of base isolated buildings: A state of the art review, Structures and Buildings, ICE 110 (1995), 186-203.

[5] M.S. Chalhoub and J.M. Kelly, Shake table test of cylindrical water tank in base isolated structures, Journal of Structural Engineering, ASCE 116(7) (1990), 1451-1472.

[6] B. Liang and T. Jia-xiang, Vibration studies of base isolated storage tanks, Computers and Structures 52 (1994), 10511059 .

[7] N.S. Kim and D.G. Lee, Pseudo-dynamic test for evaluation of seismic performance of base isolated liquid storage tanks, Engineering Structures 17(3) (1995), 198-208.

[8] P.K. Malhotra, New method for seismic isolation of liquid storage tanks, Earthquake Engineering and Structural Dynamics 26 (1997), 839-847.

[9] Y.P. Wang, M.C. Teng and K.W. Chung, Seismic isolation of rigid cylindrical tanks using friction pendulum bearing, Earthquake Engineering and Structural Dynamics 30 (2001), 1083-1099.

[10] M.K. Shrimali and R.S. Jangid, Seismic response of liquid storage tanks isolated by sliding bearings, Nuclear Engineering and Design 217 (2002), 1-20.

[11] M.A. Haroun, Vibration studies and test of liquid storage tanks, Earthquake Engineering and Structural Dynamics 11 (1983), 179-206.

[12] W.H. Robinson, Lead rubber hysteretic bearing suitable for protecting structures during earthquakes, Earthquake Engineering and Structural Dynamics 10 (1982), 593-604.

[13] Y.K. Wen, Method of random vibration of hysteretic system, Journal of Engineering Mechanics, ASCE 102 (1976), 249263.

[14] M.C. Constantinou and I.G. Tadjbakhsh, Hysteretic dampers in base isolation : Random approach, Journal of Structural Engineering, ASCE 111 (1985), 705-721.

[15] V.A. Zayas, S.S. Low and S.A. Mahin, A simple pendulum technique for achieving seismic isolation, Earthquake Spectra 6 (1990), 317-333.

[16] R.S. Jangid and T.K. Datta, Dissipation of hysteretic energy in base isolated structure, Shock and Vibration 3 (1996), 353359.

[17] M.K. Shrimali and R.S. Jangid, A comparative study of performance of various isolation systems for liquid storage tanks, International Journal of Structural Stability and Dynamics 2 (2002), 573-591. 

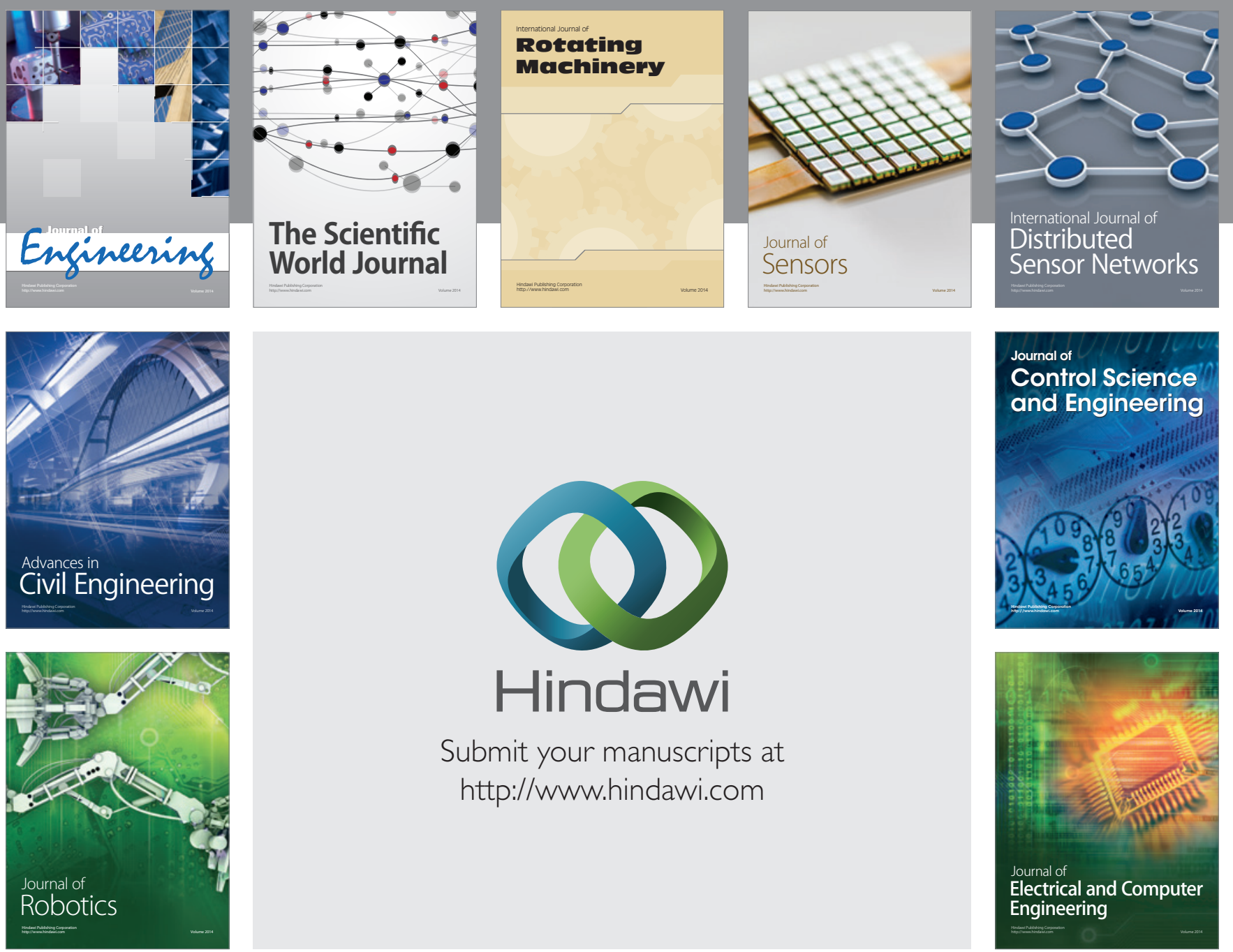

Submit your manuscripts at

http://www.hindawi.com
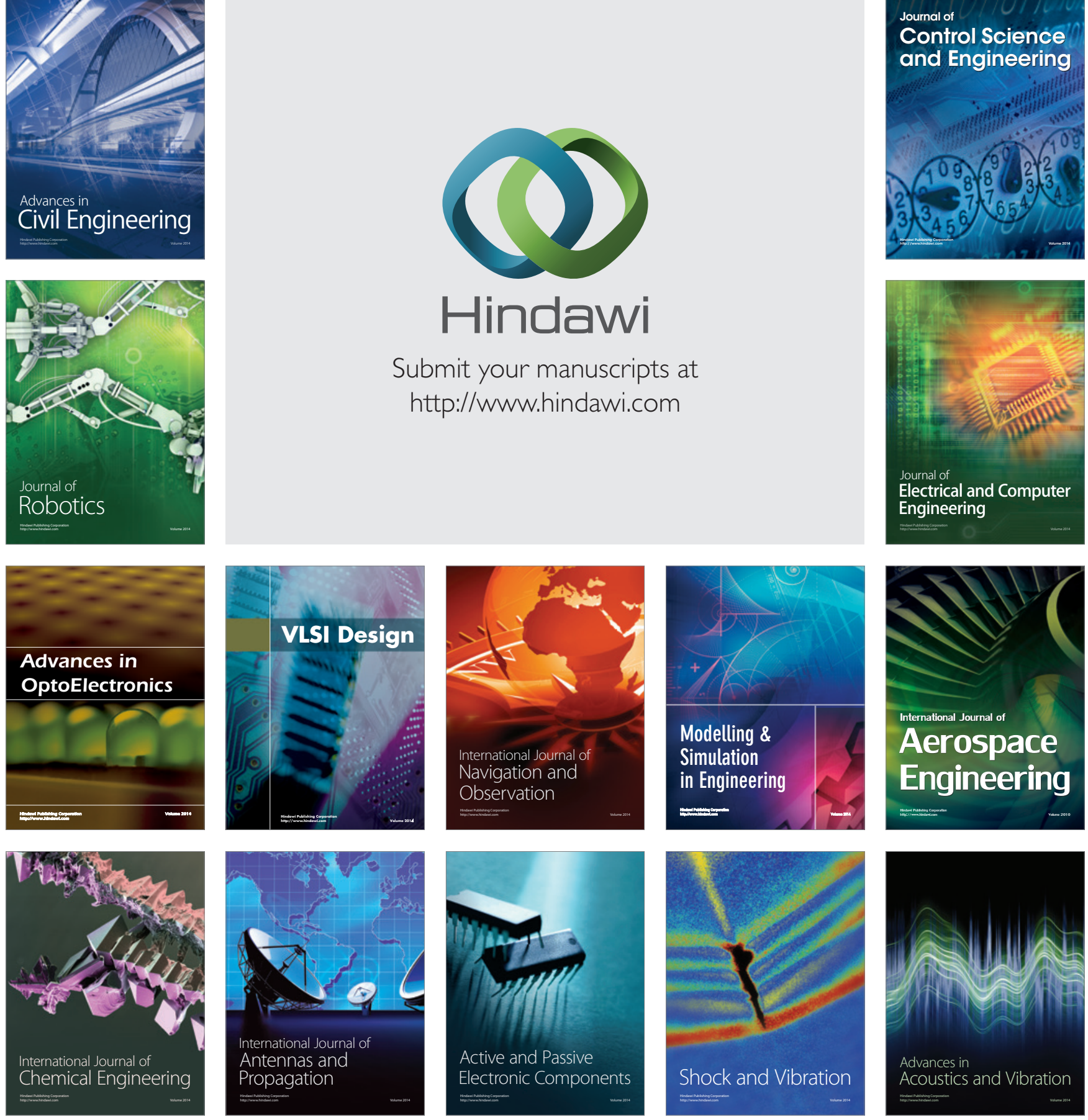